\title{
READING BEYOND THE STROKES: A SEMIOTIC ANALYSIS OF EDITORIAL CARTOONS ON A CAMPUS NEWSPAPER OF A HIGHER EDUCATIONINSTITUTION IN THE PHILIPPINES
}

\author{
Benjamin B. Mangila \\ School of Teacher Education, Josefina H. Cerilles State College \\ 7028 Dumingag, Zamboanga del Sur, Mindanao, Philippines \\ benman1586@gmail.com
}

\begin{abstract}
Editorial cartoons have an unchallenged history as a unique and important artefact in both political and cultural discourses. In journalism, they offer varied insights and may eventually alter beliefs and opinions, influence politics, trigger discussions, and give life to ideas. This paper investigates the signs and meanings of editorial cartoons published in a campus newspaper of a tertiary school in the Philippines. It anchors on Chandler's semiotic concepts in analyzing the editorial cartoons that incorporate both the Saussurean dyadic concept of signs, signifier and signified, and the Peircean triadic concept of signs as symbolic indexical, and iconic. It also considers Leymore's idea of the figure and ground, which identifies the primary, secondary, and tertiary signifiers based on their importance or impact on editorial cartoons. Analysis shows that editorial cartoons contain all types of signifiers, primary, secondary, and tertiary, which work together to effectively convey the intended meanings to its target readers. These signifiers also possess certain characteristics as being symbolic, indexical, and iconic and they blend together to enrich the editorial cartoons' intended meanings. Furthermore, these editorial cartoons illustrate the newspaper's perceptions as well as its stand on various issues and concerns relating or affecting the students and the whole academic community. Although these editorial cartoons are only published in the campus newspaper, they do not only deal with important local issues and concerns but in the national and global spheres as well.
\end{abstract}

Keywords: campus newspaper, chandler's semiotic concepts, editorial cartoons, Leymore's figure and ground, Peircean triadic concept, semiotic analysis

\section{A. INTRODUCTION}

hey say that a picture is worth a thousand words (Mesina \& Recio, 2012). For this reason, editorial cartoons play a vital role in a newspaper as it monitors the political,

Locial, and economic events of the country and the world as shown by scenes created by the cartoonist inspired from his or her surroundings (Lawate, 2012). The currency and conveyed message of an editorial cartoon differentiates it from other caricatures on a newspaper. Low, as cited by Mendoza (2016), defines an editorial cartoon as "a drawing, symbolic or representational, which makes a critical, witty or humorous point." Being an art, an editorial cartoon could trace its history back from the Reformation era as a means of argument and ridicule.

Over the years, editorial cartoons which are also known as "political cartoons", have played a very powerful role in shaping public opinion. They are mostly composed of two different components: caricature and allusion (Piedmonte-Lang, n.d.). Caricature is defined as 
visually entertaining technique of blowing up or shrinking down a genuine person's distinguishing features. Allusion, meanwhile, refers to casual reference to a situation where cartoonists employ symbols and/or words to ridicule a political scenario. The mixture of these two components would result to an influential and humorous attack on a politically important circumstance. This is more so for heads of states because, as Hoff (1966) argues that, "heads of states are putty in the hands of a political cartoonist".

It is in this light that this research is developed. Newspaper editors know that not all readers would have the patience to read through print columns and barrages of opinions. An editorial cartoon with an editorial piece summarizes the publication's stand in a certain illustration and may encourage readers to continue and read the article for details. Tayag, as cited by Cruz (1969), states that an editorial cartoon could be, and often is, more eloquent than any editorial text. Hence, it is not astonishing that people appreciate visuals more than the texts which describe or characterize the intended messages or ideas of the cartoonist. In addition, the humor that these cartoons usually convey makes them more appealing to look at than a tedious column of words. However, Ramirez (1998) posits that an editorial with humor but without a clear message is just a cartoon. As such, it is the main responsibility of the editorial cartoonist to equally combine humor and sense that the editorial cartoons are likely to convey.

According to Edwards (2007), editorial cartoons have been recognized as a unique and vital participant artefact in both cultural and political discourses. The role they play in the field of journalism could not be underestimated for they afford different insights and may consequently alter opinions and beliefs, influence politics, spark discussions, and give life to ideas. The primary intention of editorial cartoons is to stir social, political, and economic changes of a country. There may be situations where editorial cartoons which are reflective of the newspaper's stand, are not able to fulfill their primary intention of stirring changes in a country's specific aspect. As Batnag (1990), "while cartoons could be utilized as a gauge of public opinion, they do not, probably cannot, accurately reflect public opinion."

The means by which editorial cartoons are conveyed are called "signs." Signs are anything that expresses a meaning: words, images, gestures, voices, and even thoughts. They do not only portray meanings but they also convey worldviews, ideologies, and lifestyles. Chandler (2011) argues that anything can be a sign as long as someone interprets it as signifying something - referring to or standing for something other than itself. Mendoza (2016) adds that the meanings of signs are socially constructed and likewise construct the society. 
In the Philippines, periodicals have always been utilizing cartoons since the times of Kalayaan to La Solidaridad to Manila Times to Manila Chronicles and Manila Bulletin (Ladrido, 1973). Cartoons that were published during the Japanese regime were prominent as they were loaded with negative and thematic symbols, aided by particular formal symbols that "further improved negative images" (Rivera, 2005). With the proclamation of independence from Japanese clutches, editorial cartoons still remained to take part in publications and newspapers. According to Campos as cited by Mesina and Recio (2012), there came a time when negative and positive editorial cartoons were balanced. This happened during the martial law years, and this period was regarded as the "rebirth of exciting news and editorial cartoons."

Several studies have shown that institutional pressures, also seen as editorial policies, modify cartoon elements, thus creating an avenue for purposely manipulated meanings (Billoso, 1991; Campos, 1986; Casimiro, 1988; Lopez, 2008). Casimiro (1988) argues that editorial cartoons are not simply agents for creating comments and criticisms, but they also act as "indices" to editorial policies of publications where they are printed. Lopez (2008) noticed in her content and semiotic analysis that cartoonists' opinions are "screened" by editorial policies and are "packaged" in such a way that the cartoonist's opinion would heed to editorial policies and stand of the publication or newspaper. She also found that some cartoonists who still hold their ground on their opinions as reflected by their illustrations. However, most often than not, the cartoonist's opinion still has to correspond to the newspaper he or she works for. As Hoff (1966) says, political cartoonists' views must also coincide with that of the newspaper.

By analyzing editorial cartoons from a particular period and place, it may be possible for someone to get a clear glimpse of what have shaped important events at that certain time. Although they lack specific details and sufficient contents to tell a whole story, they do give hints on significant social and political developments (Mesina \& Recio, 2012). Thus, this study was conducted to explore the meanings of selected editorial cartoons that are presented on a campus newspaper, the College Journal, of the Josefina H. Cerilles State College, Dumingag, Zamboanga del Sur. Specifically, it determined the particular types of signs that were used in the editorial cartoons as well as the intended meanings or messages that the editorial cartoons wanted to convey to their readers. 


\section{B. REVIEW OF RELATED LITERATURE}

According to Zyglis (as cited in Mushohwe, 2011), an editorial cartoon consists of two main elements: graphic art and commentary. However, this definition is too broad, as it includes other types of graphic art such as comics and advertisements. Scholarly research into editorial cartoons, or cartoons in general, is a relatively new phenomenon. Zyglis (2003) added that, "a work of graphic art with commentary is an editorial cartoon only if its commentary conveys a distinct editorial message portrayed in a clever or witty manner." Although the preceding explanation appears to set the editorial cartoon apart from all other forms of graphic art, it is not without flaws. Political themes have been incorporated into some works of comic art, blurring the line between comic art and editorial cartooning.

Editorial cartoons are rich not only in lines and graphics, but also in history. It began with Leonardo da Vinci, Pieter Bruegel, and Albrecht Durer, who experimented with grotesque heads which are very similar to what we now refer to as caricature. According to Markow (as cited in Mesina \& Recio, 2012), it blossomed with the introduction of lithography, which provided a style that was ideal for political cartooning.

The popularity of editorial cartoons has continued throughout history. Editorial cartoons have a number of characteristics that distinguish them from other forms of cartooning. Furthermore, an editorial cartoonist who has the support of the free press will be extremely powerful (Cagle \& Farrington, 2007). However, the effectiveness of editorial cartoons necessitates a number of characteristics. Fine drawings, brilliant satire, bold rich tones, invented symbols, and direct technique are also required in cartoons. Being a cartoonist also necessitates being a strong draftsman with a strong understanding of character and caricature, as well as the ability to treat humor seriously and vice versa (Markow, as mentioned in Mesina $\&$ Recio, 2012).

In his descriptive content analysis, Hagape (1994) discovered that cartoons mostly used humorous themes to get their messages across. Furthermore, according to Bismonte (1992), editorial cartoons must speak for themselves, and political cartoonists must convey a message in a single frame. Bismonte's concept of an effective editorial cartoon was clearly backed up by the mere fact that a good editorial cartoon should be able to strongly stand on its own and be more than a graphic representation of the editorials with which it shares the same page (Editorial Cartooning, 2001).

Markow (as quoted in Mesina \& Recio, 2012) was backed up by a later study that stated that political cartoons must have humor, but only if they also have substance, because a humorous editorial cartoon with no substance is just that: a cartoon (Editorial Cartooning, 
2001). Cua (1982) focused on the themes of political or government affairs, crime, and contemporary social conditions, which were prevalent in editorial cartoons at the time. It must present sharp vital themes with deep meaning, according to Becker (as cited in Cua, 1982). A caricature that deals with an old event that has no current political relevance, according to Becker, loses its impact.

It is worth noting that researchers find editorial cartoons to be more eloquent to read than the actual editorial. Cartoons, according to Stantis (as cited in Cagle \& Farington, 2007), can depict an issue in "high-definition clarity better than 10,000 words." Readers are wary of wading through columns of print, and editors are well aware of this (Hoff, 1966).

A serious political issue presented in the form of a cartoon, according to Brinkman (as cited in Cua, 1982), would "drive its message home to the minds of the larger circle of average men and women, more than what long cold columns of black and white editorials can achieve." "While it is more difficult to repeat the written word or banner headline a few days after its appearance," Milenkovitch (as menyioned in Cua, 1982) clearly added, "the impact of an arresting cartoon may linger longer." "The attraction of the picture that is compared to that of the printed word is such that its mere sight amidst a sea of print is likely to excite the reader's pleasure," Cua (1982) continued.

An editorial cartoon that is paired with an editorial text serves as an extension of the text, capturing an event or situation that would take many words to describe. Finally, Cua (1982) stated that "its meaning can be easily understood" because it is "a pictorial mix of fact and fantasy liberally interspersed with humor."

\section{METHODOLOGY}

This study utilized the qualitative method, particularly content analysis, in analyzing the editorial cartoons published on a campus newspaper.

It made use of Chandler's (2011) concepts of semiotics which incorporated both the Saussurean dyadic concept of signs, the signifier and the signified, and the Peircean (1867) triadic concept of signs as symbolic, indexical, and iconic. Utilizing Chandler's (2011) semiotic concepts, the signifiers were first identified as primary, secondary, and tertiary, and were then classified as symbolic, indexical, and iconic. Furthermore, it aimed to reveal the meanings conveyed by cartoons to their readers.

The researcher's main sources of data were the editorial cartoons published on the College Journal for five school years from 2012-2017. A total of five editorial cartoons, covering five issues, were analyzed by the researcher. The five issues where these editorial cartoons were 
published were personally collected by the researcher from the College Journal Office of J.H. Cerilles State College, Dumingag, Zamboanga del Sur, Philippines.

After the editorial cartoons were collected, they were then analyzed by the researcher using Chandler's (2011) concepts of semiotics which incorporated both the Saussurean dyadic concept of signs which is composed of the signifier and the signified, and Peircean (1867) triadic concept which categorizes the signs as being symbolic, indexical, and iconic.

Furthermore, it made use of Leymore's (1975) idea of figure and ground which allows the "foregrounding" and "backgrounding" of dominant figures. The figure or "foreground" was regarded as primary signifiers while ground or "background" images and texts are secondary and tertiary signifiers. Thus, it created the format of having primary, secondary, and tertiary signs in the analysis.

\section{RESULTS AND DISCUSSION}

Signifiers Present in Editorial Cartoons and their Classification

\section{2016 Presidential Elections in the Philippines}

\section{Editorial}

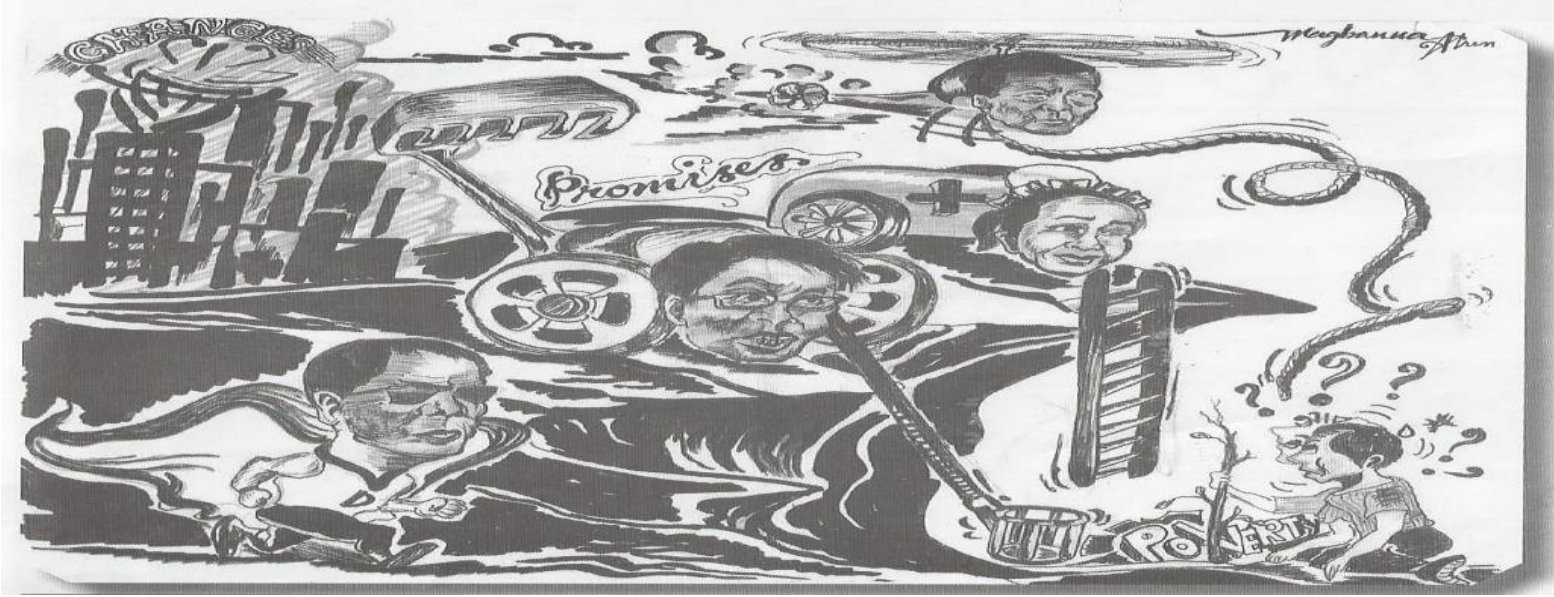

Figure 1. 2016 Presidential Elections in the Philippines

In the first editorial cartoon, there are two primary signifiers present which are Presidential Candidates and Promises. The first primary signifier, Presidential Candidates, is depicted by the images of four presidential candidates during the May 2016 National and Local Elections. These four presidential candidates include Rodrigo Duterte, Manuel Roxas II, Mary Grace Poe-Llamanzares (Grace Poe), and Jejomar Binay. The first candidate, Rodrigo Duterte, is shown as a superhero like "Superman", who is wearing a sleeveless t-shirt with an emblem consisting of letter " $\mathrm{D}$ " on the chest, a pair of eyeglasses, and a long cape and is running very fast. The second candidate, Manuel Roxas II, can be seen only with his face placed in front of 
a two-wheeled machine whose part having a basket extends to the two persons sitting under the cliff. The third candidate, Grace Poe, can also be seen only with her face that is attached to the front part of a vehicle, where a ladder coming from her extends to the two persons sitting below. The last candidate, Jejomar Binay, can also be seen having his face placed in front of the helicopter flying above, where a long rope coming from that helicopter extends to the same persons sitting below. The other primary signifier, Promises, is written above the hill at the back of the four candidates. This signifier refers to the words commonly uttered by candidates especially during election campaigns in order to show how they could improve the state of living of their constituents who are their voters so they could gain more votes from them. The secondary signifier is Poverty. This signifier is not only shown by the same word that is written below but it is also represented by the two persons sitting under the cliff, one is holding a withered plant but both of them are confused as shown by the several question marks that are placed above their heads. It can also be seen that these two persons are staring at the four presidential candidates above who they think could somehow alleviate them from their present, impoverished situations. These individuals shown here represent millions of poor Filipinos who suffer poverty largely brought about by unemployment, graft and corruption, armed conflict, etc. The tertiary signifier is Changes. Placed above the buildings, it pertains to the social and economic progress and development which were promised by the candidates during election campaigns and are hoped to experience by majority of the Filipinos especially the poor.

In the second level of analysis, it shows that this editorial cartoon uses several signs which are symbolic, indexical, and iconic. One of the primary signifiers, Presidential Candidates, is both symbolic and iconic. This signifier is symbolic because it uses conventional signs for words and for its linguistic use in the context. It is also iconic because it utilizes images similar to the four presidential candidates who ran during the national elections. The other primary signifier, Promises, is both symbolic and indexical. It is symbolic because it uses conventional signs for words and it is used linguistically in context. It is also indexical because it denotes both social and economic development which is hoped by Filipinos. Poverty, the secondary signifier, is symbolic, indexical, and iconic. It is symbolic because it utilizes conventional signs for words. It is indexical because it signals deficiency or scarcity of some economic resources as shown by the withered plant that is being held by one of the individuals. It is also iconic because it depicts the true situation of poor Filipinos who wear old and torn clothes and stay in slums. The third signifier, Changes, is also symbolic, indexical, and iconic. As a symbol, it uses conventional signs like letters for words. As an index, it connotes transformation if the 
proposed changes are to take place. As an icon, it uses images which are analogous to buildings and other skyscrapers that are also found in real life.

\section{Changing Values of Filipino Youth Today}

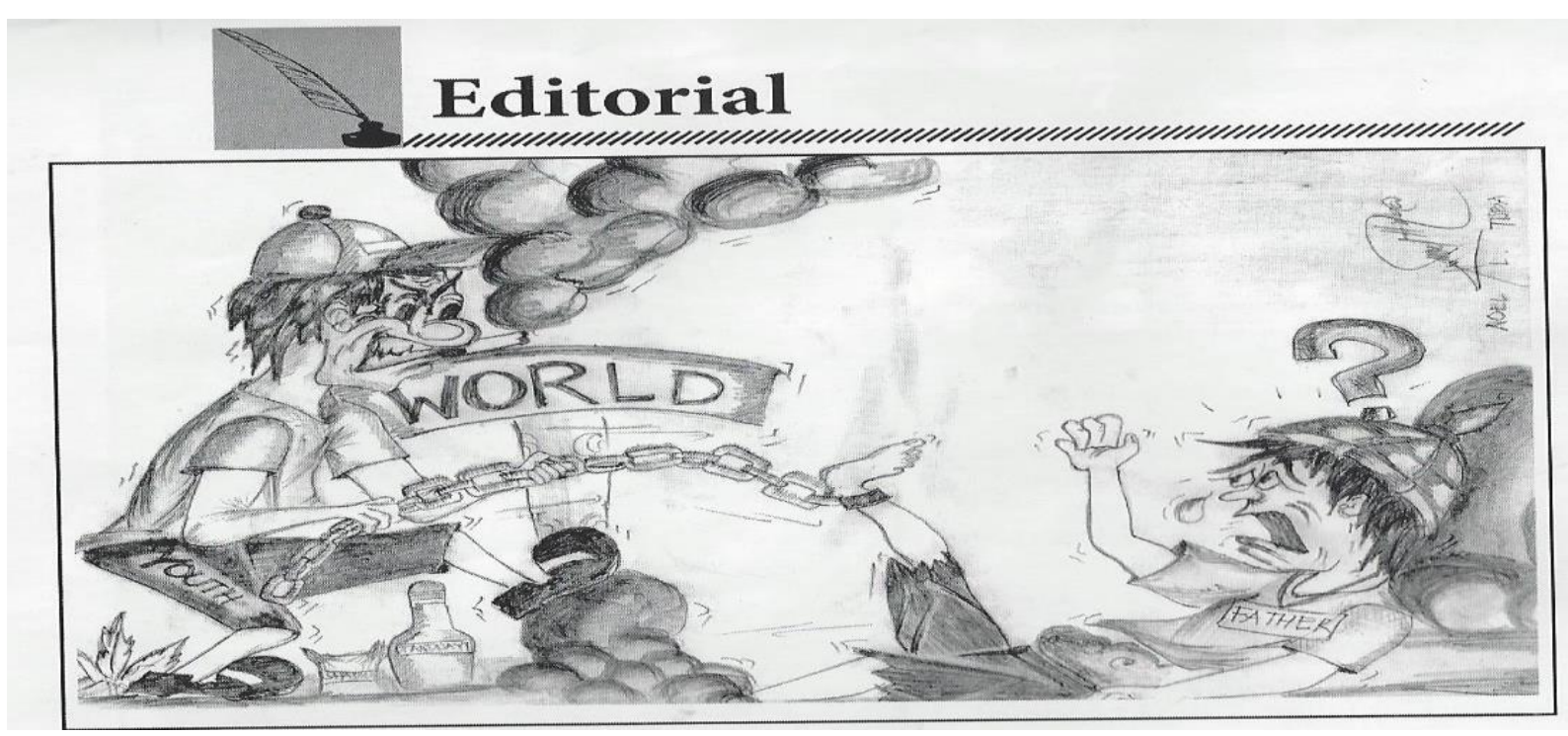

Figure 2. Changing Values of Today's Filipino Youth

In the second editorial cartoon, the primary signifier is Filipino Youth. This signifier is represented by the young man who has already changed which is believed to have been influenced by globalization. This young man is seen having some vices like smoking, drinking, and even taking illegal drugs like shabu and marijuana. Furthermore, this young man can be seen mockingly pulling the chain that is being tied to his father who is shown crying and is confused about what is happening to his son. This signifier depicts the changing values of the Filipino youth today who were once considered by our national hero Dr. Jose P. Rizal as the hope of our country, but then they have become the liabilities of our society nowadays. The secondary signifier is Concerned Parent. This signifier is portrayed as a concerned father who is being tied to a chain that is sarcastically being pulled by his young son. This father is also shown here crying, as one sees a tear falling from his eyes, as well as being confused, as one could see a question mark on his head, as he tries to know what is really happening to his beloved son. The tertiary signifier is Globalization. This signifier is represented by the word "World", in all capital letters and is boldly written on a wooden sign board. As a signifier, it pertains to the positive and negative effects of globalization which can have an impact on the socio-economic lives and the viewpoints and values of Filipino youth today.

The signs in this editorial cartoon also possess three characteristics of a sign. The primary signifier, Filipino Youth, is symbolic, indexical, and iconic. It is symbolic because it uses the conventional signs for words and is used linguistically in context. It is also indexical because it 
shows the smoke which signals the presence of fire as illustrated by the lighted cigarette at the same time shows the unusual behavior of a young man who is under the influence of alcohol and illegal drugs as evidenced by the presence of a liquor (Tanduay), a sachet of shabu, and marijuana leaves. It is also iconic because it displays several images similar to what can be found in real life. For instance, the image of a young man which could represent the Filipino youth today, the bottle of a popular liquor (that of Tanduay), a sachet (that of the shabu), and the leaves (that of the marijuana plant). The secondary signifier, Concerned Parent, is also symbolic, indexical, and iconic. It is symbolic for it utilizes the conventional signs for words shown on the word written on the father's shirt. It is indexical because it shows how worried and confused the father is on his son as signaled by the presence of a question mark over his head. It is iconic because it depicts an image of a parent, particularly that of a father, who is also concerned with the welfare of his children. The tertiary signifier, Globalization, is both symbolic and indexical. It is symbolic because it also uses conventional signs for words as shown on the word written on the wooden sign board. It is also indexical because it does not only act as an agent which influences the young man to change his old ways but also as a barrier which puts the young man away from his father's influence.

\section{Accreditation of the College}

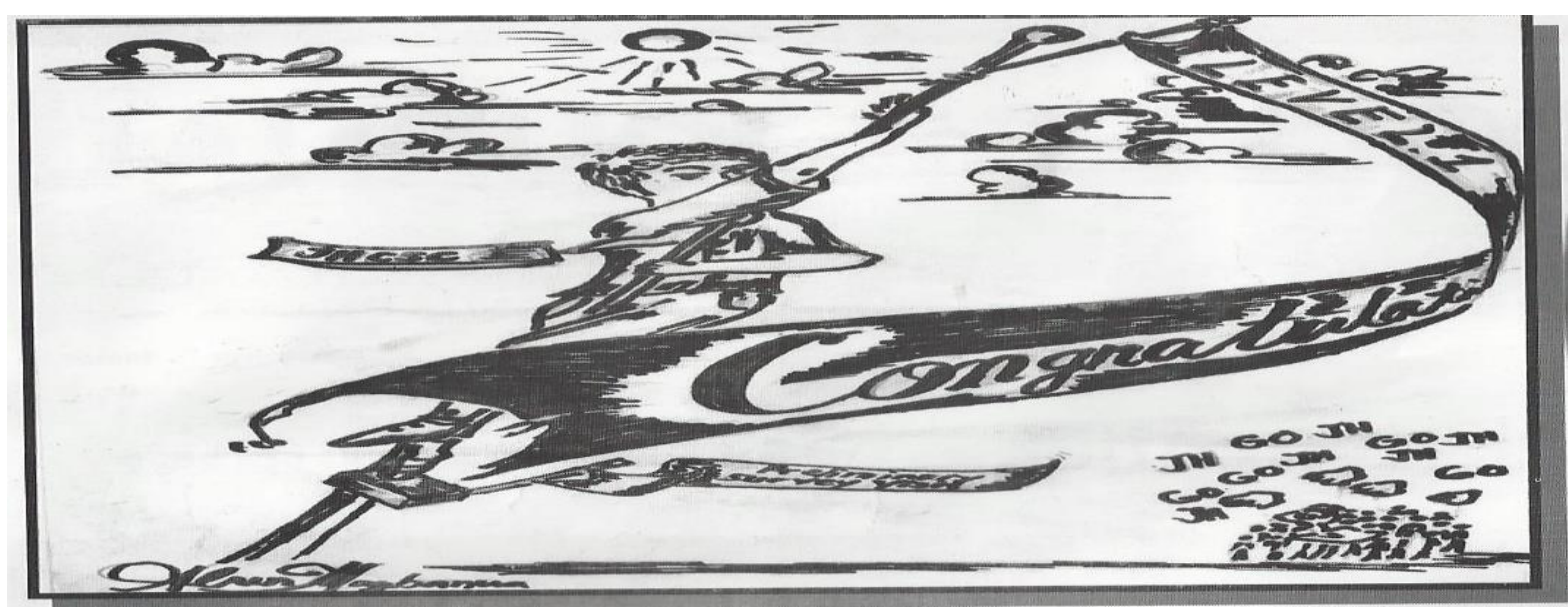

Figure 3. College Accreditation

In the third editorial cartoon, the primary signifier is Accreditation. This signifier is not indicated here but it is depicted through the longest banner raised over the pole which congratulates the institution, J.H. Cerilles State College, for passing the Preliminary Survey Visit (PSV), the initial step of the accreditation process. Furthermore, it tells that being able to pass the Accreditation (Level 1) means that the institution has successfully met the minimum requirements and standards set by the government through CHEd for all higher education institutions in the country. 
Preliminary Survey Visit (PSV) is the secondary signifier. As clearly shown, this signifier is placed at the first step of the pole which indicates that it is the initial step that any tertiary learning institution must undergo and pass first before it will be subjected to accreditation. Before the PSV is conducted, necessary documents must be prepared by the institution in terms of several areas to be evaluated which include VMGO (Vision, Mission, Goals, and Objectives), Faculty, Curriculum and Instruction, Support to Students, Research, Extension and Community Involvement, Library, Physical Plant, Facilities, and Laboratories, and Administration. The tertiary signifier is JHCSC. This signifier stands for J.H. Cerilles State College which is considered as the only state college in Zamboanga del Sur. As clearly shown, this signifier is labeled on a small banner being held by the student while he is trying to reach the edge of the pole where the longest banner is raised. Moreover, this signifier is shown by the phrase "Go JH (short for JHCSC)", being shouted by some human figures drawn below which compose the whole academic community.

The signifiers in this editorial cartoon can be described as symbolic, indexical, and iconic. The primary signifier, Accreditation, is both symbolic and indexical. This signifier is symbolic because even though the word is not clearly indicated in the editorial cartoon but it is represented by the phrase "LEVEL 1" which uses the conventional signs for words. It is also indexical because it tells us not only about the institution's efficiency but also the quality of the educational services that an accredited institution can offer to its clienteles. The secondary signifier, Preliminary Survey Visit, is both symbolic and indexical. It is symbolic for it uses conventional signs for words and for its linguistic use in the context. It is also indexical because passing the PSV would generally tell us that the institution is ready to embark on the stringent accreditation process. The tertiary signifier is JHCSC which is both symbolic and iconic. It is symbolic because it uses conventional signs such as letters for words. It is iconic because it makes use of an image of a boy and other human figures which represent the whole academic community composed of administrators, faculty, non-teaching staff, students, and parents.

\section{ASEAN Integration}

In the fourth editorial cartoon, the primary signifier is $A S E A N$ which stands for the Association of South East Asian Nations. As a signifier, it is depicted not only through the acronym written on the waving flag but it is represented by a young man wearing a traditional costume, particularly that of a Vietnamese or Thai, and is busy pulling the rope where another young man on the other side is clinging unto it. ASEAN is a regional intergovernmental organization established on August 8, 1967 which comprises Indonesia, Malaysia, Philippines, 
Singapore, Thailand, Brunei, Cambodia, Laos, Myanmar, and Vietnam. As an organization, it promotes Pan-Asianism and intergovernmental cooperation and facilitates economic, political, security, military, educational, and socio-cultural integration among its members and Asian states. The secondary signifier is JHCSC which stands for J.H. Cerilles State College. This signifier is not only depicted by the written word but is represented by a young man wearing a traditional kimono and buli hat and clinging to the rope being pulled by another man. This man represents the whole academic community made up of administrators, faculty, nonteaching personnel, students, and parents. The action of the young man here tells that the whole community is ready for ASEAN integration. The tertiary signifier is Culture which is depicted by the word written on the rope. Furthermore, the rope drawn represents Culture which becomes the force that binds ASEAN and JHCSC, represented by the two young men.

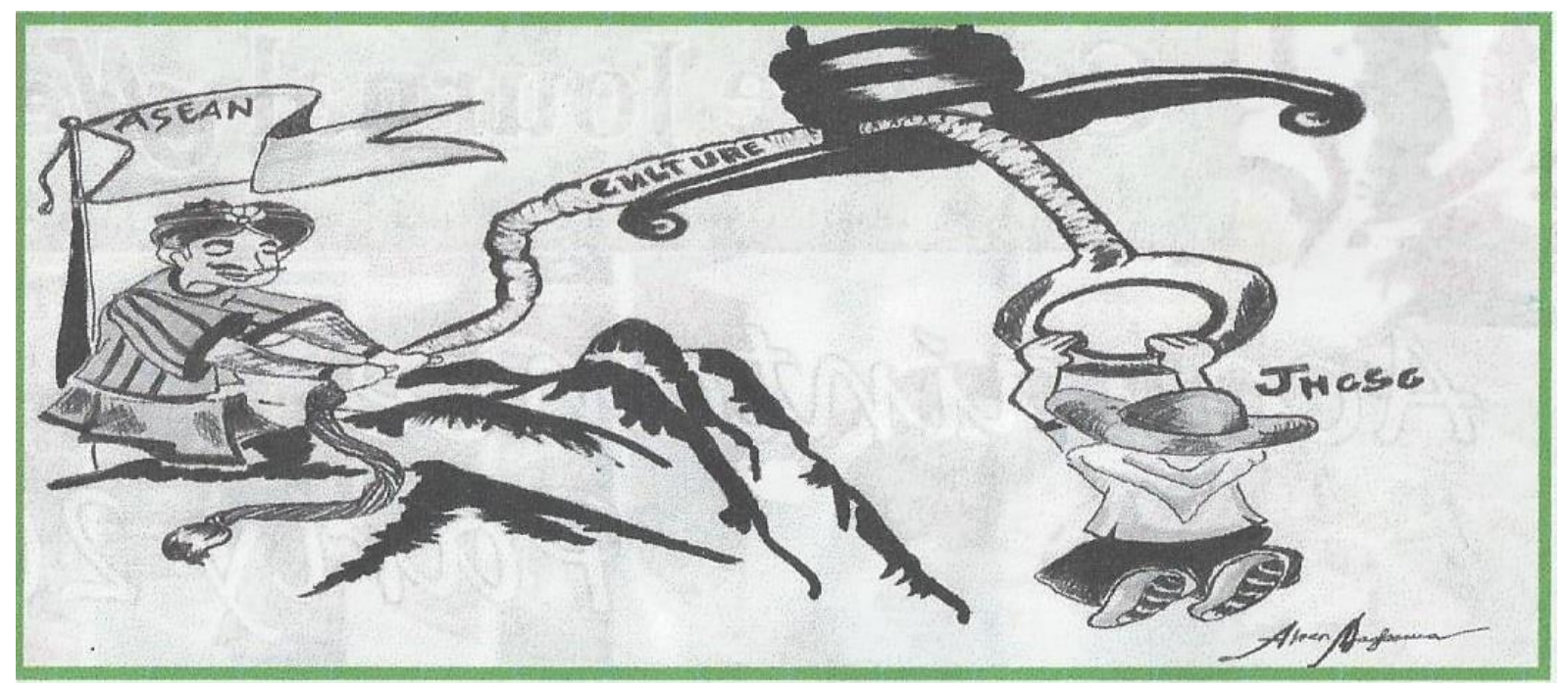

Figure 4. ASEAN Integration

The signifiers in this editorial cartoon can be symbolic, indexical, and iconic. The primary signifier, $A S E A N$, is both symbolic and iconic. It is symbolic for it uses conventional signs for words. It is also iconic because it uses an image of a person, probably that of a Vietnamese or Thai, who is wearing a traditional costume popular especially among Southeast Asian nations. The secondary signifier, JHCSC, is both symbolic and iconic. It is also symbolic for it uses conventional signs for words. It is also iconic because it is represented by an image that is analogous to that of a young Filipino, wearing the traditional kimono, and the buli hat worn by farmers. Meanwhile, the tertiary signifier, Culture, is both symbolic and indexical. It is symbolic because it makes use of the conventional signs like letters. It is indexical because it serves as an instrument which binds together ASEAN and JHCSC as one community. 


\section{Attaining Long Lasting Peace in Mindanao}

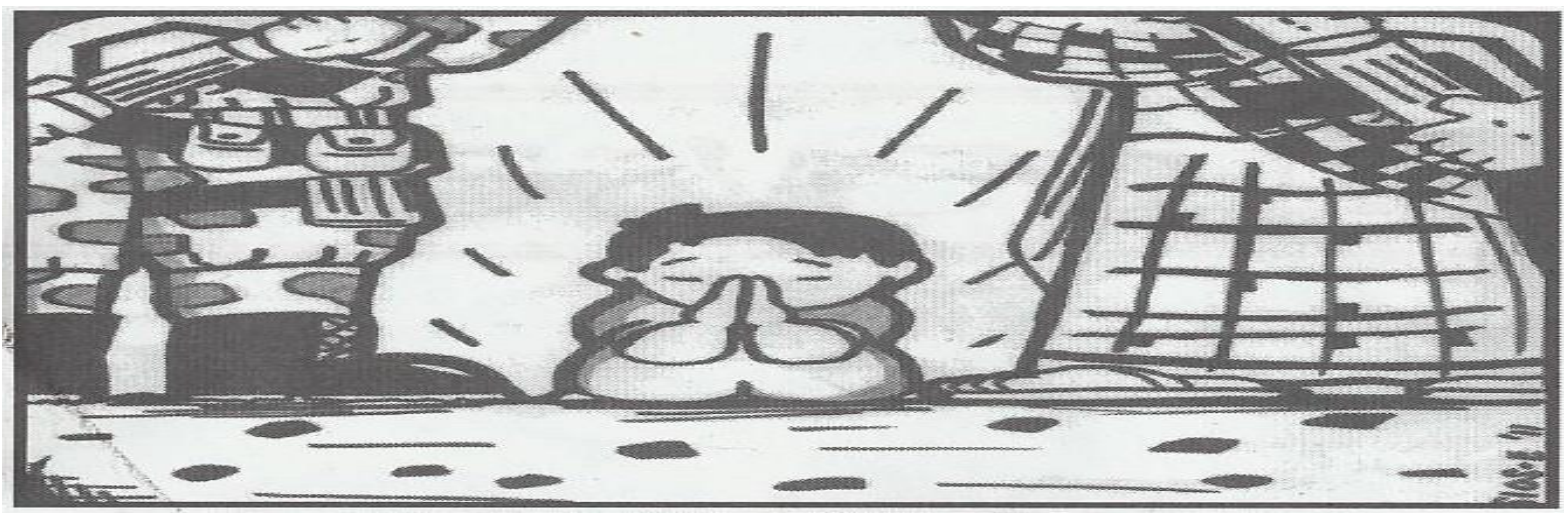

Figure 5. Attaining Long Lasting Peace in Mindanao

In the fifth editorial cartoon, the primary signifier is All-Out-Justice Declaration. This signifier is not shown directly through the actual words written but it is depicted by the images of the two armed but faceless persons standing beside the child who is praying seriously. The person standing at the right side of the child who is wearing a camouflage while at the same time bringing a rifle represents the government's armed forces. Meanwhile, the other person standing at the left side of the child wearing another uniform and also bringing a rifle represents the rebel group, the Moro Islamic Liberation Front (MILF). It can be recalled that the Aquino government declared in 2011 an all-out-justice instead amidst the persistent public call for an all-out-war against the MILF because of the death of the 19 soldiers who were killed in the clash which took place in Basilan on October 22, 2011. The government had its own rationale for rejecting the call for an all-out-war and adopting instead the so-called allout-justice through peaceful means. It believed that waging war might not be the right thing to do at that moment as it would increase violence and bloodshed among soldiers, armed rebels, and even innocent civilians. The secondary signifier is Peaceful Negotiations. This signifier is clearly depicted by a child who is praying fervently in the midst of the two conflicting groups, the government's troops and the rebel group. The child here actually represents the innocent Filipino civilians, both young and old, who have always become the victims of the decades-long conflict in Mindanao. The child can be seen in the figure who is praying, and just like the others, his prayer is for the attainment of a long-lasting peace in Mindanao that is only achieved through peaceful negotiations and not an all-out-war against the enemies. The tertiary signifier is Peaceful Mindanao. Although not stated explicitly in the cartoon, this signifier can be depicted through the long-term peace that Mindanaoans can enjoy when an all-outjustice is declared instead of an all-out-war against the MILF and other rebel groups. 
Mindanao has already become a battleground for decades-long conflict and this has not helped Mindanao achieve its social and economic growth. It is believed then that attaining peace through a bloody war is not true peace at all but attaining peace through peaceful means is what actually constitutes true peace.

Similar to other signifiers, these signifiers also possess certain characteristics as being symbolic, indexical, and iconic. The primary signifier, All-Out-Justice Declaration, is both indexical and iconic. It is indexical because it clearly indicates that the government is trying its best to attain the long-term peace in Mindanao through using peaceful means and not a violent all-out-war against the MILF and other rebel groups in the region. It is iconic because it uses images similar to those of a soldier and a rebel who are both faceless but bringing with them their weapons. The secondary signifier which is Peaceful Negotiations is also iconic. It is iconic because it shows an image of a child who is incessantly and earnestly praying so that peace will be attained and restored in Mindanao not through a bloody war but by peaceful means like having peace talks. Meanwhile, the tertiary signifier, Peaceful Mindanao, is indexical as it clearly indicates that this will be the result if the government troops and rebel groups unite and work together in order to fully attain peace through peaceful means.

\section{Signifieds (Meanings) Conveyed by Editorial Cartoons}

The first editorial cartoon was published few months after the May 2016 National and Local Elections. With Presidential Candidates and Promises as its primary signifiers, it aims to convey a message to its readers about the promises that presidential candidates always make during election campaigns. Although a common scenario in Philippine politics and in other countries around the world, election campaigns have become the best avenues for both traditional and young politicians to present their own political agenda or their platform of governance. In any election campaign, what always remains the same is not the lineup of candidates busy campaigning just to earn votes but the promises each candidate makes to the audience who are their constituents. In this editorial cartoon, the four candidates are not shown as ordinary individuals but as extraordinary ones with superpowers who are believed can institute changes or reforms and make the lives of poor Filipinos better. To poor Filipinos, every election is a chance where they could not only see these political candidates but to hear their sweet promises. However, usually in the end, these promises are not kept and still remain just the sweet words that were first uttered by these politicians during campaigns.

The second editorial cartoon conveys another important message that is addressed to the Filipino youth. Similar to its primary signifier, it talks about the changing values of Filipino youth today. Shown as one who has several vices, this young man represents millions of 
Filipino youth who have become the opposite of what an ideal Filipino youth is as described by our national hero Dr. Jose P. Rizal. Considered as the hope of our nation, the Filipino youth have become the liabilities of our society today. Engaged in smoking, drinking, and even taking illegal drugs, the Filipino youth have transformed and this change in them is believed to have happened because of globalization. Globalization has been one of the major factors why there are changes not only in the social, cultural, and economic conditions in our country's society but also in the deteriorating values of Filipino youth. Because of globalization, the Filipino youth are heavily exposed to influence of other cultures which is largely brought by Internet, television, and radio. Furthermore, this change in the Filipino youth has caught the attention of parents who are concerned with the welfare of their children and this also becomes another problem that our country has to deal with. This editorial cartoon does not only show what situation our youth are really in but it also tells us an important thing, that is, to protect and save them from getting more ill.

Unlike the previous editorial cartoons, the third editorial cartoon does not deal with national issues and concerns but on the important events that happen inside the campus. Similar to its primary signifier, it deals with the accreditation of some curricular programs of J.H. Cerilles State College-Dumingag Campus. The curricular programs which underwent the proposed accreditation that time included BSEd, BEEd, BSA, and BSIT. Published a few months after, it congratulates the institution for successfully passing the Preliminary Survey Visit (PSV), conducted by the Accrediting Agencies of Chartered Colleges and Universities in the Philippines, Inc. (AACCUP). Considered an initial step, passing the PSV implies that JHCSC-Dumingag Campus is now ready for accreditation after it has adequately prepared the needed requirements set by the government. Furthermore, it entails that if the institution passes the accreditation process, it would mean that the institution has successfully met the minimum requirements and standards set by CHEd. As an accredited tertiary institution, JHCSC-Dumingag Campus would then be fully committed to excellence and service and ensure that its practices are then of the highest quality.

The fourth editorial cartoon conveys to its readers a message of unity and cooperation not only among us Filipinos but also among the citizens of other ASEAN nations. Similar to its primary signifier, it deals with ASEAN Integration that is largely depicted by a rope that is being pulled by the two individuals who both represent the other ASEAN nationalities and the Filipinos. This editorial cartoon also tells that it is culture, represented by the rope in the cartoon, that strongly binds Filipinos and other ASEAN nationalities together as one community and this also proves that there is harmony despite their cultural diversities. As an 
organization, ASEAN has become an avenue where the social, cultural, educational, and even economic exchanges take place among the citizens of these nations. It also tells us that J.H. Cerilles State College, as one of the institutions of higher learning in the Philippines, has to cope with this development and must make itself ready for the ASEAN Integration. Furthermore, it implies that because of this ASEAN Integration, there will be more doors of opportunities that will be opened especially for our graduates as our country also joins and unites with the rest of other ASEAN countries in this mutual exchange.

The last editorial cartoon depicts one of the perennial problems that the country has been facing for so many decades and that is the attainment of long-lasting peace in Mindanao. Formerly dubbed as the land of promise, Mindanao has now become a land of guns and wars because of the decades-long conflicts not only between the Christians and Muslims but also between the government troops and rebel groups such as MILF, MNLF, and others. Depicting a child who is praying between two faceless but armed individuals, this editorial cartoon tells us that it is not an all-out-war declaration which is the real answer in attaining long-lasting peace in Mindanao but it can only be realized through an-all-out-justice declaration. Compared with the all-out-war, an all-out-justice declaration strongly advocates the attainment of peace in Mindanao through peaceful means, that is, through peace talks. It also tells us that war is not really the solution at all but it only makes things more complicated. Furthermore, it entails that when Mindanao has already become really peaceful, then that's the time that it would experience true progress and development.

\section{E. CONCLUSION}

This study endeavors to critically analyze and reveal the meanings of the editorial cartoons that are published in the campus newspaper of a higher education institution in the Philippines. The in-depth analyses of the editorial cartoons made by the researcher utilizing primarily Chandler's semiotic concepts with consideration of Leymore's idea of figure and ground reveal that editorial cartoons, through the editorial cartoonists' creative and imaginative minds, employ several signs (signifiers) in order to effectively convey the intended meanings or messages (signifieds) to their target readers, specifically the college students. These signifiers, consist of both texts and images and are identified as primary, secondary, and tertiary, complement as well as work together in these editorial cartoons to make more realistic visual imageries or clearer views of some local, national, and global issues and concerns that matter most not only to the students as their main audience but to the entire academic community as well. Furthermore, these signifiers possess certain characteristics such 
as being symbolic, indexical, and iconic which are in turn, blend and work together to shape or enrich the meanings or messages that these editorial cartoons wanted to express to their readers. Even though these editorial cartoons are only published in a campus newspaper, they also deal with the national and global issues and concerns in order to clearly convey deeper awareness and understanding about some social phenomena that are also happening in the readers' world.

\section{REFERENCES}

Batnag, O. (1990). Editorial cartoons and public opinion. Undergraduate thesis, University of the Philippines Diliman, Quezon City.

Billoso, N. (1991). The Cory government as portrayed in editorial cartoons. Undergraduate thesis, University of the Philippines, Diliman, Quezon City.

Bismonte, C. O. (1992). A Bismonte folio of editorial cartoons. No publication information.

Cagle, D. \& Farrington, B. (2007). The best political cartoons of the year. USA: Cagle Cartoons, Inc.

Campos, J. C. (1986). A comparative analysis of the editorial cartoons of the Bulletin Today. Undergraduate thesis, University of the Philippines, Diliman, Quezon City.

Casimiro, M. C. (1988). The editorial cartoon as history. Undergraduate thesis, University of the Philippines, Diliman, Quezon City.

Chandler, D. (2011). Semiotics for beginners. 13 October 2017. http://www.aber.ac.uk/media/Documents/S4B/semiotic.html.

College Journal. The official student publication of JHCSC-Dumingag campus. 2011-2017. J.H. Cerilles State College, Dumingag, Zamboanga del Sur.

Cruz, A. C. (1969). Editorial cartoons '69: Selections from the Manila Press. Manila: The National Library.

Cruz, A. C. (1969). Editorial cartoons '69: selections from the Manila Press. Manila: The National Library.

De Saussure, F. (1965). Course in general linguistics. Illinois: Open Court Publishing."Editorial cartooning." Quill, (2001). 89(5), 37. Retrieved from EBSCOhost.

Edwards, J. L. (2007). Media history and marginalized form: The editorial cartoon profession considered. Review of Communication 7(1), 127-130.

Hagape, M. (1994). A descriptive content analysis of the editorial cartoons of the Philippine Daily Inquirer during the first one hundred days of the Ramos Administration. (Unpublished undergraduate thesis, University of the Philippines Diliman). 
Hoff, S. (1966). Political cartooning: The art of cartooning. New York, USA: Stravon Educational Press.

Ladrido, R. C. (1973). The newspaper as an institution and the editorial cartoons in two Manila daily newspapers. Undergraduate thesis, University of the Philippines, Diliman, Quezon City.

Lawate, M. M. (2012). Importance of political cartoons in newspapers. 13 October 2017. http://repository.christuniversity.in/1717/1/1024026 meghana lawate.pdf.

Leymore, V. L. (1975). Hidden myth: Structure and symbolism in advertising. Pennsylvania: Harper and Row Publishers, Inc.

Lopez, B. T. (2008). A comparative content and semiotic analysis of the editorial cartoons of Manila Bulletin and Philippine Daily Inquirer from 2004 to 2007. Undergraduate thesis, University of the Philippines, Diliman, Quezon City.

Mendoza, R. (2016). Semiotic concepts of editorial cartoons. 14 October 2017. http:/ / www.noveltyjournals.com/download.php?file $=$ Semiotic $\% 20$ Concepts $\% 20$ of $\%$ 20Editorial $\%$ 20Cartoons-511.pdf\&act=book.

Mesina, K. L. T. \& Recio, M. (2012). Reading beyond the strokes: A study on P-Noy's portrayal in Philippine Daily Inquirer's, The Philippine Star's and Manila Bulletin's editorial cartoons from the election period to his first year as president. 14 October 2017.

http://iskwiki.upd.edu.ph/images/a/a5/Mesina\%2C_Karen_Lou_Tolentino_Re cio $\% 2$ C_Eloisa_Mana

lus_042012_Reading_beyond_the_strokes_A_study_on_Pnoys_portrayal_in_PDI $\% 2$

C_PhilStar_and_MB_editorial_cartoons_from_election_period_to_his_first_year_as_ president.pdf.

Mushohwe, K. (2011). An analysis of selected editorial cartoons published during Zimbabwe's $2008 \quad$ elections. $13 \quad$ October 2017. http:/ / contentpro.seals.ac.za/iii/cpro/app?id $=5042234018339531$ \&itemId $=1006367$ \&lang $=$ eng\&service $=$ blob\&suite $=$ def.

Peirce, C. S. (1867). The philosophy of signs. Bloomington, Indiana: Indiana University Press.

Piedmonte-Lang, Z. (n.d.) Comedy or commentary? The history of political cartoons. 13 October 2017. http://www.meadowmontessori.org/events/history/media/Comedyor Commentary.pdf.

Rivera, H.Y. (2005). Patterns of continuity and change: Imaging the Japanese in Philippine editorial cartoons, 1930-1941 and 1946-1956. Quezon City: Ateneo de Manila Press.

Ramirez, M. P. (1998). Editorial cartoons. Quill, 86 (5), 22.

Zyglis, A. (2003). The art of editorial cartooning. New York: Canisius College. 